\title{
Viewpoint
}

\section{A model for continuous quality improvement in small scale practices}

\author{
H Geboers, R Grol, W van den Bosch, $\mathrm{H}$ van den Hoogen, H Mokkink, P van Montfort, \\ $\mathrm{H}$ Oltheten
}

Centre for Quality of Care Research (WOK), Department of General Medicine, University of Nijmegen, PO Box 9101, $6500 \mathrm{HB}$ Nijmegen, the Netherlands H Geboers, general practitioner, research fellow

R Grol, professor of general practice

$\mathrm{W}$ van den Bosch, professor of general practice

$\mathrm{H}$ van den Hoogen, statistician

H Mokkink,

methodologist

$\mathrm{P}$ van Montfort, health

scientist

$\mathrm{H}$ Oltheten, general practitioner

Correspondence to: Dr Geboers.

Accepted 24 November 1998
During the past decade new models for quality improvement in health care were developed based on experiences in industry. ${ }^{1}$ These models became known as total quality management or continuous quality improvement and are now widely and successfully used in larger healthcare organisations. ${ }^{2-12}$ In general practice several tools are used to improve care, such as vocational training, continuous medical education, peer review, audit, and guideline development. ${ }^{13}$ Although valuable, these tools usually focus more on improving professional performance than on comprehensive care provision delivered by teams. Little is known about the use of continuous quality improvement in small scale general practice.

The question is whether it is possible to translate the principles of continuous quality improvement into a model for quality improvement for general practice. Simply adopting the strategies of continuous quality improvement used in hospitals or larger organisations may fail because of the specific characteristics of general practice. ${ }^{14}$ Most of these practices have, for example, a hierarchical structure in which the general practitioner (GP) is not only the manager but also is often the owner. In many countries general practices have a small staff who lack the time for quality improvement activities. ${ }^{15}$

The aim of this article is to reflect on the applicability of continuous quality improvement in small scale practices. Firstly, the characteristics of general practice will be discussed. Secondly, the essential elements of continuous quality improvement are presented by giving a short review of previous publications. Finally, these elements are translated into a framework of practical possibilities for quality improvement in general practice, which results in a model for quality improvement that may be feasible and applicable in small scale general practice. Examples from a study on quality management in general practice done in the Netherlands are used to illustrate the model. ${ }^{16}{ }^{17}$

\section{Characteristics of general practice}

General practice differs in many respects from specialist care or institutional care. In general, three characteristics of general practice can be discerned. These are related to the type of health problems presented, the type of care provided, and the type of organisation.

\section{HEALTH PROBLEMS}

The health problems with which patients present in general practice are often unspecified and self limiting. In many cases the medical hypothesis a GP works on is a complaint and not a diagnosis. On the other hand, a GP takes care of many patients with chronic diseases such as diabetes, hypertension, and chronic obstructive pulmonary disease.

TYPE OF CARE

The care that GPs provide is characterised by the fact that patients consult their GP for a first diagnosis. They have easy access to this type of care. GPs have long standing relationships with many of their patients, making general practice particularly suited to the supervision of chronic diseases and to perform preventive medicine or community care.

\section{TYPE OF ORGANISATION}

Finally, general practices are often organisations with a small staff. A single handed practice often consists of no more than a GP and a practice assistant. They usually have a high workload. In most countries, GPs own their practices and the GP usually also manages the practice. In larger practices, such as healthcare centres, a managing director is appointed. Although in some countries GPs extend their working field into hospitals, they mostly work isolated from other care providers. Conversely, they collaborate with many disciplines to manage the care their patients need.

Such characteristics ask for specific approaches to managing improvement in a systematic and continuous way.

\section{Core elements of continuous quality improvement}

According to Berwick, quality improvement consists of a wide array of managerial and organisational activities designed to help managers to understand and streamline production processes, to remove waste and unpredictability, and to achieve previously unprecedented levels of performance. ${ }^{18}$ As continuous quality improvement is a collection of activities, different authorities assign different levels of importance 
Table 1 Elements of continuous quality improvement and a framework for small scale practices

\begin{tabular}{|c|c|c|}
\hline Core elements & Consequences & A framework for small scale practices \\
\hline Management & $\begin{array}{l}\text { Leadership } \\
\text { Mission and shared vision } \\
\text { Targets } \\
\text { Resources } \\
\text { Favourable changes in organisation }\end{array}$ & $\begin{array}{l}\text { Set targets based on realistic expectations towards practice development and long term policy of the } \\
\text { professional organisation } \\
\text { Make plans on improvement } \\
\text { Establish priorities towards subjects that particularly need improvement } \\
\text { Designate a GP as the quality coordinator } \\
\text { Hold quality meetings with all staff at regular intervals (for example, once a month) } \\
\text { Establish a quality board in practice } \\
\text { Integrate the activities in daily work }\end{array}$ \\
\hline Based on factual data & $\begin{array}{l}\text { Performance measures } \\
\text { Analysis of the organisation } \\
\text { Satisfaction }\end{array}$ & $\begin{array}{l}\text { Collect data on specific subjects (according to priorities set or projects run and including patient } \\
\text { satisfaction), if possible form electronic medical files (other sources include insurers, laboratories, } \\
\text { pharmacists, appraisals, etc) } \\
\text { Make annual reports on outcomes of care } \\
\text { Make annual reports on improvement activities }\end{array}$ \\
\hline Systematic approach & $\begin{array}{l}\text { Planned activities } \\
\text { Use of the quality cycle } \\
\text { Use of specific tools and techniques } \\
\text { Learn from experience }\end{array}$ & $\begin{array}{l}\text { Run small improvement projects on prioritised issues (management of chronic disease, preventive } \\
\text { activities, accessibility, workload) } \\
\text { Use tools and techniques that are simple to use and not time consuming (brainstorming, analysis of } \\
\text { strengths and weaknesses, flow charts, cause and effect diagrams, etc) } \\
\text { Aim at changes in which existing processes are adapted or re-engineered (and build on } \\
\text { experience) (ideas to improve processes can come from peer review, continuing medical } \\
\text { education, guidelines, publications, etc) }\end{array}$ \\
\hline Collaboration & $\begin{array}{l}\text { Everyone involved } \\
\text { Positive attitude towards continuous } \\
\text { quality improvement } \\
\text { Team building } \\
\text { Participation }\end{array}$ & $\begin{array}{l}\text { Involve everyone in quality improvement activities (everyone is aware of tasks and responsibilities) } \\
\text { Build teams for systematic improvement activities } \\
\text { Involve patients (and other external customers) in improvement activities }\end{array}$ \\
\hline
\end{tabular}

to associated techniques and ideas. When giving an overview of previous publications on continuous quality improvement it seems appropriate to condense these activities into four elements, which we will forthwith refer to as the core elements of continuous quality improvement: (a) a leading role of management, (b) actions based on factual data, (c) a systematic approach, and (d) close collaboration in quality improvement among all who are involved in the care processes, explicitly those involving patients (table 1). ${ }^{2}{ }^{18-20}$

\section{MANAGEMENT}

In an organisation that uses continuous quality improvement it is clear what needs to be improved and what changes have to be made to bring improvement. Improvement is intended and specific aims are set; the goals are clear, realistic, and challenging. ${ }^{41}{ }^{21}$ Priorities are set because not all goals can be achieved at once. ${ }^{182-24}$ Leadership is needed to get continuous quality improvement started, to disseminate it throughout the organisation, and to sustain it. $^{5}{ }^{25-27}$ Managing improvement demands leadership that motivates people and facilitates continuous quality improvement. ${ }^{22} 28-30$ Resources such as time,

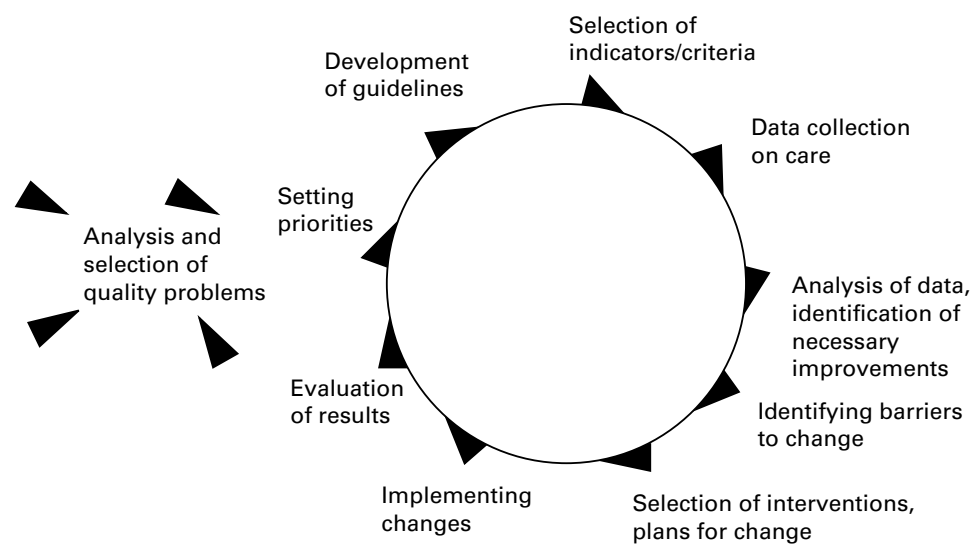

Figure 1 The PDSA cycle. Reprinted with permission from Grol R. Kwaliteitsbevordering voor en door huisartsen. Utrect: NHG/LHV/WOK, 1995. room, possibilities to communicate, and knowledge of change are important also. ${ }^{19}$ In brief, practical managerial consequences for continuous quality improvement include leadership, a shared vision, clear targets, and sufficient resources.

BASED ON FACTUAL DATA

Reliable up-to-date facts about the practice and its performance are the starting point for effective decision making and improvement. ${ }^{31}{ }^{32}$ Assessing patients' needs and expectations towards, and satisfaction with, the organisation can, for instance, yield useful data for quality improvement. ${ }^{33}$ Data can convince people that the changes made are really an improvement. Also, maintaining the gains of improvement activities can only be achieved by monitoring performance and outcomes. ${ }^{34} 35$ The practical consequences thus include measuring performance, analysing crucial processes, and collecting data on consumers' needs and satisfaction. For monitoring purposes these measurements are best repeated at regular intervals.

\section{SYSTEMATIC APPROACH}

Improvement is a planned activity, an improvement project, in which the quality cycle (PDSA cycle) is used as a process of decision making (fig 1). ${ }^{231}$ 36-38 Many tools and techniques are available to help improvement teams go through the quality cycle. ${ }^{19} 3940$ Furthermore, improvement is made step by step. The more complex the processes and the higher the organisational aims, the more steps it takes to achieve excellence. ${ }^{19}{ }^{41-44}$ Practically, this means that an organisation initiates improvement projects, using the quality cycle and its tools and techniques, and that it learns from experience.

\section{COLLABORATION}

In a typical continuous quality improvement culture everyone is involved in improvement. Everyone tries to help others in the organisation 
to do their job better. If anyone is not involved, improvement fails. Everyone should be aware of the targets of the organisation and the responsibility for it. ${ }^{19}{ }^{45}$ People in an organisation work in teams related to care processes in which they are each other's customers and suppliers. Quality improvement needs patients to be involved because they are part of the organisational processes too. ${ }^{19} 37$ 46-50 This means that continuous quality improvement asks for an organisationwide awareness of the customer-supplier relationship of everyone within and between organisations, and with patients. Collaboration includes team building, involvement of all staff, and a positive attitude towards continuous quality improvement.

\section{Framework for continuous quality} improvement in small scale practices

We have translated these core elements of continuous quality improvement into a framework for small scale practices in which the specific characteristics of general practice are taken into account; table 1 outlines this framework. In this section we will discuss the consequences of continuous quality improvement for small scale practices and suggestions as to how practices may cope with these consequences.

To manage continuous quality improvement in general practice the most effective leader has to play the leading part. In small scale practices we can expect the GP, who is the owner and manager, to take the role of the quality coordinator. In larger practices it could be more effective if a quality board, sometimes chaired by a practice manager, has this task. Targets for improvement include the possibilities and challenges of the practice itself as well as the priorities of professional organisations, such as the national medical association and the college of general practitioners. Management includes implementing favourable changes. Quality meetings with all staff during working hours on a regular monthly basis can be of great help. In these meetings the state of improvement activities is discussed and teams for improvement projects are formed. Practices can gradually come to a more specific and shared vision by making plans for improvement and annually revising them. It is important that, especially with a small staff and a lack of other resources, priorities are set for subjects that qualify for quality improvement.

General practice has many opportunities to base actions on factual data. Many practices use an electronic medical file from which essential data on medical performance can be easily derived. Data on specific subjects, according to the priorities set, are available. If a practice is not computerised, essential outcome data may still be available. For example, referral rates can be accessed through insurance companies, pharmacists can provide data on prescriptions, laboratories on test orders, etc. Annual reports on performance and outcomes of care make it possible to evaluate progress. Annual plans and reports on improvement can also help practices to set their targets. In addition to this, practices can collect data on specific subjects in improvement projects.
A systematic approach is best guaranteed if practices run small, easy to handle improvement projects. Lack of time and resources sets the limit to the size and number of quality improvement projects that small scale practices can run. Tools and techniques, including methods to collect data on the indicators of improvement projects, should be simple to use and not time consuming. The role of the practice assistant is important. Brainstorming, analysis of strengths and weaknesses, tally sheets, Pareto-analysis, flow charts, and cause and effect diagrams may be useful, although flow charts and cause and effect diagrams are time consuming and only recommended if large or complex processes have to be rebuilt. ${ }^{29}{ }^{30}$ In most of the projects, practices could confine themselves to adapting the existing processes. Peer review groups and continuing medical education provide GPs with the opportunity to compare their performance with others.

In small scale practices everyone is already aware of their tasks and responsibilities with regard to collaboration. It seems only a small step to involve everyone in quality improvement. Although it will not be easy to involve patients in improvement projects at first, gaining their participation in improvement teams is the challenge.

\section{Model for continuous quality improvement}

Having established the framework of continuous quality improvement in general practice, we can now create a model that can be introduced into practices. To do so, it should be kept in mind that the use of continuous quality improvement will evolve gradually, bringing about many cultural changes. At the introduction therefore the model should at least include those aspects that are crucial for continuous quality improvement and those which we expect to be feasible and applicable in general practice. In our opinion the model for continuous quality improvement should include:

- Involving all staff

- Setting targets for improvement

- Establishing priorities for subjects that especially need improvement

- Doing small and easy to handle improvement projects

- Using the quality cycle and easy to use tools and techniques.

The model should also include favourable changes in the practice organisation, such as:

- Having regular practice meetings on quality improvement with all staff

- Enhancing leadership by designating a quality coordinator

- Making annual plans on quality improvement

- Making annual reports on quality improvement activities and results.

This model was introduced into a small number of practices in a feasibility study which is also reported in this issue of the journal (p36). ${ }^{51}$ To illustrate the model we present two examples of how continuous quality 


\begin{tabular}{|c|c|c|c|}
\hline Improve & \multicolumn{2}{|c|}{ Important } & Keep this way \\
\hline \multicolumn{2}{|c|}{$\begin{array}{l}\text { - Glucose concentrations and } \\
\text { consequences for } \\
\text { medication } \\
\text { - Annual check ups in } \\
\text { accordance with standards } \\
\text { - Practice protocol } \\
\text { - Time } \\
\text { - Registration }\end{array}$} & & $\begin{array}{l}\text { - Taking glucose test } \\
\text { - Other laboratory tests } \\
\text { (cholesterol/creatinin) } \\
\text { and urinalysis } \\
\text { - Dietary measures } \\
\text { - Ophthalmic check ups }\end{array}$ \\
\hline Bad & & & Good \\
\hline \multicolumn{4}{|c|}{$\begin{array}{l}\text { - Special training of practice } \\
\text { assistant } \\
\text { - } \mathrm{HbA}_{\mathrm{c}}\end{array}$} \\
\hline Do not mind & Uni & $r \operatorname{tant}$ & Save time/costs \\
\hline
\end{tabular}

Figure 2 Analysis of strengths and weaknesses on diabetes care $(\mathrm{HbA1}=$ glycated haemoglobin). strengths and weaknesses was done to gain insight into the current performance on diabetes care and to specify the aims of the project (fig 2). Based on this analysis the practice team chose to do regular check ups and achieve acceptable blood glucose concentrations as its aims for improving the quality of diabetes care. They added self monitoring of blood glucose concentrations by patients as an aim of the improvement project because this was of special interest to the GP. With the facilitator's help they used the quality cycle to do the project. They first set criteria on regular check ups and blood glucose concentrations using the Dutch College of General Practitioners' guidelines on type II diabetes. The practice set its own criteria for patients who monitored their own blood glucose concentration because there were no guidelines available on the subject. Data were collected prospectively on these indicators for three months. The practice continued by designing a new process of care. Plans for change consisted of a consulting hour for regular check ups by the practice assistant and annual check ups by the GP. A protocol was made which provided the practice assistant with guidelines on when to refer patients to the GP. Instructions for patients on self monitoring blood glucose concentrations were also developed. The outlines of instructions for the practice assistant were put on a plastic card, which she could refer to during consultation. No specific arrangements were made for implementing the plans for change. The GP and his assistant seemed to be sufficiently motivated to adhere to their agreements by simply discussing the changes. After nine months, project data were collected again to evaluate the project. The number of patients who received their three month check ups increased from 23 $(51 \%)$ to $36(80 \%)$ out of 45 patients with diabetes. Furthermore, the number of patients whose blood glucose concentrations met the criteria increased from six out of $23(26 \%)$ to 18 out of $36(50 \%)$, and the number of patients who monitored their own blood glucose concentrations rose from six to 17 . The practice decided to monitor the outcomes on diabetes care once a year in the future.

\section{Evaluation}

Both the GP and the practice assistant were enthusiastic about the results of their first improvement project. They concluded that they had found the model useful, particularly the improvement project. They found facilitation was needed most during the quality meetings and in using the tools and techniques. They both agreed that the facilitation period was too short for a full implementation of continuous quality improvement. To continue working with the model they started a project on hypertension care.

CONTINUOUS QUALITY IMPROVEMENT IN A HEALTHCARE CENTRE

Practice setting

A second example is taken from a healthcare centre in the western part of the Netherlands. The staff consists of six GPs, seven practice 
assistants, and a receptionist. The practice is responsible for the general health care of 12000 people. Physiotherapists, social workers, and home care nurses have consultation rooms in the same building. The healthcare centre has a part time managing director. The practice participates in the vocational training of GPs. Each GP has a minor specialty, such as minor surgery, rectoscopia, or injections in joints. Specialist consultants visit the practice regularly to examine patients together with the GP. Every year the practice makes an annual report. The practice is fully computerised and data on medical performance can be easily derived from the electronic medical files. The GPs and their assistants have monthly meetings in which they discuss the progress of activities.

\section{Introduction of the model}

At the introduction of continuous quality improvement the facilitator focused on favourable changes in practice organisation which they had not already made. She established monthly quality meetings between the managing director, the practice assistants, and the GPs. This all-staff quality meeting was regarded as a quality board. One of the GPs was designated as the quality coordinator, and he also chaired the regular meetings. The facilitator then focused on setting priorities for further improvement.

\section{Improvement projects}

The quality board decided to start with three small scale improvement projects simultaneously. The board briefed teams for each improvement project. The progress of the improvement projects was discussed during the monthly quality meetings. The improvement teams used brainstorming and cause and effect diagrams as tools to identify problems and possible changes. They used flowcharts as a tool to make clear what the new processes would look like after the introduction of change. During the introduction period, which lasted 18 months, nine projects were started of which four were multidisciplinary. Home care nurses participated in a project on diabetes care; physiotherapists participated in a project on low back pain; and physiotherapists and home care nurses were involved in a project on rehabilitation. Another project on cervical smears was done in collaboration with the other general practices of the town. A project on inherited breast cancer was undertaken in collaboration with the university. Projects in which only GPs and practice assistants were involved concerned hypertension care, the way in which patients were charged for medical aid, improvement of the appointment schedule, and vaccination against influenza. The facilitator spent much effort on underlining the importance of the quality cycle to the improvement projects. It was not always possible to prevent the teams from making plans for change before having collected essential data on the subject. Protocols on performance were made in all projects.
Evaluation

At the end of the introduction period the quality coordinator concluded that they had made progress in the management of quality improvement, collaboration, and in applying a systematic approach, but that they still were not focused enough on data collection. To emphasise the importance of the cultural change that had taken place, they chose collaboration on quality as a central theme of the conference that they held to celebrate their 25 th anniversary.

\section{Conclusions}

In larger healthcare organisations such as hospitals, continuous quality improvement has already proved to be a proper way to improve the quality of care. For smaller organisations such as general practices, adapted models are necessary. The model presented in this paper might be suited for general practice as well as other office based practices such as dentists and physiotherapists. Even small scale practices have many opportunities to introduce continuous quality improvement. Some of the activities are already done by practices. Some activities are time consuming, such as quality meetings, collecting data, and making annual reports. Some activities are difficult to do and need facilitation from outside the practice. This may be provided by professional organisations, by local or regional boards for health care, or by health authorities. GPs and staff gradually need to learn to work with the tools and techniques. More importantly, practices need to incorporate a practice culture in which improving the care process is a continuous aim. ${ }^{20}$ It may be useful to provide courses on quality management. In these courses practices can gain knowledge on data collection and analysis and on running improvement projects, and they can learn how to build teams and coordinate them.

Although the model for continuous quality improvement seems feasible for small scale practices and its applicability could be enhanced by facilitation, practices may find some aspects difficult to adopt. One of the most striking aspects may be involving patients in quality improvement. Although it is probably one of the most important elements of continuous quality improvement, one could not expect practices to ask their patients to participate in their activities until the practice had gained some experience. Another issue that could certainly evoke difficulties is the culture change that continuous quality improvement brings about. Looking back upon the characteristics of general practice one could expect that, specifically, the organisational structure of practices would be the breeding ground for obstacles to the use of continuous quality improvement. Favourable changes in practice organisation from working with continuous quality improvement may well disappear soon after the facilitator has left the practice, and other activities may also disappear under pressure of limited time and resources. Is it possible for GPs to set aside part of their autonomy as owner and manager in 
favour of involving others in quality improvement? Owing to cultural changes, the introduction of continuous quality improvement might well be the biggest and most challenging improvement project a practice can run. If we want practices to accept the challenge of adopting continuous quality improvement we need to consider whether it is worth all the effort and which aspects of continuous quality improvement are most important for general practice. Research will have to take on that challenge.

1 Merry M. Total quality management for physicians, translating the new paradigm. Qual Rev Bull 1990;16:1015 .

2 Berwick DM. Ten key lessons for quality improvement. Curing Health Care. San Francisco: Jossey-Bass, 1990:14458.

3 Shortell SM, O'Brien JL, Carman JM, et al. Assessing the impact of continuous quality improvement/total quality management: concept versus implementation. Health Serv Res 1995:30:377-401.

4 Berwick DM. Heal thyself or heal thy system: can doctors help to improve medical care? Quality in Health Care 1992; 1(suppl):S2-8.

5 Berwick DM. Continuous improvement as an ideal in health care. New Engl f Med 1989;320:53-6.

6 Duncan RP, Fleming EC, Todd GG. Implementing a continuous quality improvement in a community hospital. Qual Rev Bull 1991;17:106-12.

7 Lammers J, Cretin S, Gilman S, et al. Total quality management in hospitals. Medical Care 1996;34:463-78.

8 O'Leary DS. Accreditation in the quality improvement model, a vision for tomorrow. Qual Rev Bull 1991;17:72-7.

9 Swanson TK, Eilers GM. Physician and staff acceptance of CQ. Fam Med 1994;26:583-6.

10 Pachciarz JA, Abbott MI, Gorman B, et al. Continuous quality improvement of PAP smears in an ambulatory care quality improvement of PAP smears in

11 Sullivan N, Frentzel KU. A patient transport pilot quality improvement team. Qual Rev Bull 1992;18:215-21.

12 Boyle Creps L, Coffey RJ, Warner PA. Integrating TQM and QA at the university of Michigan Medical Centre. Qual Rev Bull 1990;16:250-8.

13 Grol R, Baker R, Roberts R, et al. Systems for quality improvement in general practice. European fournal of General Practice. 1997;3:65-8.

14 Gustafson DH, Schoots Hundt A. Findings of innovation research applied to quality management principles for

15 Lawrence M, Packwood T. Adapting total quality management for general practice: evaluation of a programme. Ouality in Health Care 1996;5:151-8.

16 Geboers H, van Montfort P, Grol R, et al. Ontwikkeling van een kwaliteitssysteem in de huisartspraktijk. Nijmegen, the Netherlands: Eindrapportage, Centre for Quality of Care Research, 1996.

17 Geboers H, van Montfort P, Grijpink G, et al. Kwaliteitsverbetering in de kleine beroepspraktijk: een voorbeeld van een verbeterproject in de huisartspraktijk. Kwaliteit en Zorg 1996;4:138-44

18 Berwick DM. Peer review and quality management: are they compatible? Qual Rev Bull 1990;16:246-51.

19 Berwick DM. Foundations of quality management. Curing health care. San Francisco: Jossey-Bass, 1990:29-45.

20 Batalden PB, Stoltz P. A framework for the continual improvement of health care: building and applying professional improvement knowledge to test changes in daily work. Fournal on Quality improvement 1993;19:424-52.

21 Irvine D. Focus on the practice. Managing for quality in general practice. Newcastle: University of Newcastle upon Tyne, 1990:41-57.
22 Al-Assaf AF. Data management for total quality. In: AF Al-Assaf, Schmele JA, editors. Textbook of total quality in health care. Delray Bay, Florida: St Lucie Press, 1993:12356.

23 Dale B, Payne BJ. The quality improvement process in service areas. Managing quality. Hertford: Philip Allan, 1990.

24 Langley GJ, Nolan KM, Nolan TM. The foundation of improvement. Quality Progress 1994;27:81-6.

25 Milakovich ME. Creating a total quality health environment. Health Care Manage Rev 1991;16:9-20.

26 Kaluzny AD. McLaughlin CP. Managing transitions: assuring the adoption and impact of TQM. Oual Rev Bull 1992; 18:380-4.

27 Coffey RJ, Jones L, Kowalski A. Asking effective questions; tools, methods and strategies. Fournal on Quality Improvement 1993;19:454-64

28 Baird R, Cadenhead S, Schmele JA. The implementation of total quality. In: AF Al-Assaf, Schmele JA, editors. Textbook of total quality in health care. St Lucie Press, 1993:91-101.

29 Batalden PB, Buchanan ED. Industrial models of quality improvement. In: Goldfield N, Nash DN, editors. Providing quality care, the challenge to clinicians. Philadelphia: College of Physicians 1989:133-55.

30 Van de Honert A, Broersma H. Project management. Utrecht: Teleac, 1995.

31 Irvine D, Irvine S. What is audit? Making sense of audit. Oxford: Oxford University Press, 1991:16-18.

32 Grol R. Quality of care in general practice: into the next century. Huisarts Wet 1993;36:467-72.

33 Wensing M. Patients evaluate general practice. Dissertation. University of Nijmegen, the Netherlands, 1997.

34 Schofield Th. Practice reports and profiles. In: Lawrence M, Schofield T, editors. Medical audit in primary health care. Oxford: Oxford University Press, 1993.

35 Donabedian A. The role of outcomes in quality assessment and assurance. Qual Rev Bull 1992;18:356-60.

36 Woollass T. First steps in TQM part 3: the role of TQM facilitators. Audit Trends 1994;2:179-81.

37 Donabedian A. Quality assurance in health care: consumer's role. Quality in Health Care 1992;1:247-51.

38 Hutchinson A. Primary care quality improvement; a positive response to external factors. Huisarts Wet 1993;36:458-62.

39 Rethans J, Westin S, Hays R. Methods for quality assessment in general practice. Family Practice 1996;13: 468-76

40 Dale B, Boaden RJ, Wilcox M. Difficulties in the use of quality management tools and techniques. Quality and its applications. Congressbook of first international conference on quality and its applications. Newcastle: University of Newcastle upon Tyne ,1993:633-6.

41 Berwick D. Holding and extending the gains. Curing health care. San Francisco: Jossey-Bass, 1990:134-44.

42 Gilbert J. How to eat an elephant: a slice by slice guide to total quality management. Sevenoaks; Tudor, 1992.

43 Young MJ, Ward R, McCarthy B. Continuously improving primary care; physician participation in quality management. fournal on Quality Improvement 1994;20:120-6.

44 Grol R. Implementing guidelines in general practice care. Quality in Health care 1992;1:184-91.

45 Woollass T. First steps in TQM part 2. Audit trends 1994;2 $128-31$.

46 Woollass T. First steps in TQM part 1. Audit trends 1994;2: 77-9

47 Berwick D. A primer on leading the improvement of systems. BMF 1996;312:619-22.

48 Wakefield DS, Cyphert ST, Murray J. Understanding patient centred care in the context of TQM and CQI: a patient centred care in the context of TQM and CQI: a 20:152-61.

49 Firth-Cozens J. Building teams for effective audit. Quality in Health Care 1992;1:252-5.

50 Juran D. Achieving sustained quantifiable results in an interdepartmental QI project: quality improvement teams. Fournal on Quality Improvement 1994;20:105-19.

51 Geboers $H$, Van der Horst $M$, Mokkink $H$, et al. Setting up improvement projects in small scale primary care practices: feasibility of using a model of continuous quality improvement. Quality in Health Care 1999;8:36-42. 